\title{
The Pleasure of Being Aggressive in Male Incarcerated Criminals
}

\author{
J. Martín Ramírez ${ }^{* 1, \dagger}$, Luis Millana ${ }^{1}$, Maria P. Toldos-Romero ${ }^{2}$, M.-Claude Bonniot-Cabanac ${ }^{3}$ and \\ Michel Cabanac ${ }^{3}$
}

${ }^{1}$ Universidad Complutense Madrid, ${ }^{2}$ Universidad de Alcalá, ${ }^{3}$ Université Laval Québec

\begin{abstract}
Maximization of pleasure (hedonicity) is a major mechanism in human decision-making by optimizing behavior, as previous research has shown on both sensory pleasure and purely mental pleasure (such as playing videogames or solving mathematical problems). Our group also documented that pleasure is a major factor in decision-making in social situations related to interpersonal aggression: people tend to make aggressive behavioral decisions as a function of the resulting pleasure. The present study tried to verify whether this trend was also found in inmates. To our knowledge, this is the first investigation on the relationship between pleasure and aggression performed in a prison. Fifty three male inmates in a Spanish prison condemned for severe legal transgressions and serving long detention were compared with seventy five male university students who served as controls. They responded to self-reported questionnaires devised to examine how hedonicity influences decision-making in the case of aggressiveness. Socially conflictive situations were described, with four alternative options ranging from passive to highly aggressive response. A similar bell-shaped trend was present in both populations -aggressive behaviors of medium intensity were rated as significantly less unpleasant than the most passive and most aggressive behaviors-, even though the degree of hedonicity was significantly higher in the inmates, who rated mild and moderate aggressive responses as pleasurable. Inmates also voted for an unexpected lower of aggressiveness than controls, which may be explained by social desirability. Conclusion: the sametrend is found in both populations: mild aggressive behavior may be pleasurable to the aggressor, but only up to a certain level. But this seems to be stronger in inmates: they showed hedonicity when experiencing higher level of aggression. Such a result is consistent with a fundamental role of hedonicity in decision making.
\end{abstract}

Keywords: Aggressiveness, hedonicity, emotion, prison immates, decision making.

\section{INTRODUCTION}

The general purpose of the present study is to offer relevant evidence on the paramount role of hedonicity (pleasure or displeasure) in decision-making about violence. The specific population under study was prison inmates because these subjects are especially important in aggression research. For example, a sample of criminals would be expected to contain more aggressive persons than would be predicted by the base rate for aggression in the general population (Barratt \& Slaughter, 1998). And prison inmates are also believed to be more prone to violence than the general population.

People make countless decisions every day, ranging from ones that are barely noticed and soon forgotten, to others that are highly consequential. In addition to having practical significance, decision-making plays a central role in many academic disciplines: virtually all the social sciences -including psychology, sociology, economics, political science, and law- rely on models of decision-making behavior. This combination of practical and scholarly factors has motivated great interest in how decisions are and should

*Address correspondence to this author at the Psychobiology Department, Universidad Complutense Madrid, Pico de la Pala 6, 28792 Miraflores de la Sierra, Spain; Tel: 34918444 695; E-mail: mramirez@med.ucm.es

JMR is Professor of Pychobiology at UCM; some of this research was completed while the senior author was a Research Fellow at the Kennedy School of Government, Harvard University, and MCB-C and MC were at UCM as Distinguished Visiting Researchers. be made. Research has uncovered substantial and systematic regularities in how people make decisions and has led to the formulation of general psychological principles that characterize decision-making behavior (LeBoeuf \& Shafir, 2005).

A review of the behavioral decision-making literature shows peoples' preferences to be highly malleable and systematically affected by a host of factors, one of which is hedonicity. An eventual theoretical background about models of behavioral decision-making could be based on the general theory on hedonicity, derived from a rational choice background. According to the theory of reasoned action (Fishbein \& Ajzen, 1975), personal attitudes act as mediating variables influencing behavior to the extent that they influence intentions to engage in that behavior (Schreurs $e t$ al., 2005). A similar, more updated, consideration is Ajzen theory of planned behavior: broad fundamental life values can influence the decision to engage or not in a behavior indirectly, through their impact on beliefs and attitudes. He says literally: "intentions to perform behaviors of different kinds can be predicted with high accuracy from attitudes toward the behavior, subjective norms, and perceived behavioral control; and these intentions, together with perceptions of behavioral control, account for considerable variance in actual behavior. Attitudes, subjective norms, and perceived behavioral control are shown to be related to appropriate sets of salient behavioral, normative, and control beliefs about the behavior, but the exact nature of these relations is still uncertain" (Ajzen, 1991). 
We have chosen as an alternative another decisionmaking model because, although Ajzen's theory (Ajzen, 1991) is useful for understanding beliefs and attitudes as predictors of intentions (Lowe, Eves, \& Carroll, 2002), our hypothesis is based on feelings instead. Besides that, the uncertainty pointed out by Ajzen seems to be largely -and probably totally- removed when the hedonic dimension of consciousness is taken into account (Cabanac, 1971, 1992) see also (Cabanac, Guillaume, Balasko, \& Fleury, 2002; Cabanac, Pouliot, \& Everett, 1997).

Our model, which conceptualizes decision-making as mental prioritizing, requires a common currency to rank motivations and assess trade-offs, as postulated by McFarland and Sibly (1975) and by McNamara and Houston (1986). Various motivations competing for access to this final common path must be able to 'talk to one another' in order for the brain to rank their priority. A series of interdisciplinary studies allowed us to conclude that this common currency is the hedonic dimension of consciousness. In fact, our suggestion on the role of pleasure in decision-making indeed started within physiology (Cabanac, 1979; Cabanac, Duclaux, \& Spector, 1971). Then it was extended to other pleasures, such as money (Cabanac, 1986; K. G. Johnson \& Cabanac, 1983). Then to all motivations and decisions (Cabanac, 1992, 1996) as, eventually, maximization of pleasure was found in other realms of purely mental functioning optimization activity, such as enjoying poetry or video games, ethics, and mental calculus (Balaskó \& Cabanac, 1998; Cabanac et al., 2002; Cabanac et al., 1997). The present piece of work explores the role of pleasure in decision making, adding a new dimension, the social one, to the general concept that maximizing pleasure is the way decisions are made (Cabanac, 1992; Ramírez \& Cabanac, 2003).

Conventional wisdom seems to corroborate the expectation that aggression can give pleasure. For instance, violent films are likely to be popular because spectators derive pleasure from watching them, or because some angry people enjoy hitting a punching bag, or hunters tend to place more weight on self-enhancement values of power and achievement (Hrubes, Ajzen, \& Daigle, 2001). Sadism could be another example. It is therefore not surprising that aggressiveness may also take place in sports (Russell, 2004).

An old theory broadly related to the link between hedonicity and aggression may be Freud's catharsis, in which venting one's anger will produce a positive improvement in one's psychological state refusing to express anger causes destructive feelings. Although nowdays it is largely discredited and empirically false, in the sense that aggression may fail to reduce subsequent aggression (Geen \& Quanty, 1977), the hypothesis might actually have a kernel of truth: people may be aggressive in the hope that doing so will enable them to feel better, and it does sometimes feel good. Aggression thus occasionally creates positive emotions, or vice versa, the goal of hedonic maximization may be a cause of aggression (Bushman, Baumeister, \& Phillips, 2001). Even more, a recent study has found that dopamine, also known as the brain's "pleasure chemical because its fun-loving reputation," is also highly active while someone experiences pain; it appears that dopamine acts as an interface between stress, pain, and emotions, or between physical and emotional events, and that it is activated with both positive and negative stimuli (Zubieta, Yau, \& Scott, 2006).

Previous research of our group explored the amount of hedonicity aroused in situations involving more or less aggressive responses to unpleasant situations, documenting for the first time that pleasure is a major factor in social situations related to interpersonal aggression in 'normal' population (Ramírez, Bonniot-Cabanac, \& Cabanac, 2003, 2005). Participants were asked to rate the pleasure or displeasure experienced in several minor conflicting social situations, and to decide how they would solve these situations. Several behavioral alternatives were given, from passive non-aggressive behavior to aggressive responses of rising intensities. People tended to make aggressive behavioral decisions as a function of the resulting pleasure: passive behavior and most aggressive behaviors were rated as unpleasant, but mild and moderate aggressive responses provided some pleasure to the aggressor in decisions. The moderate level of aggressiveness was the selected preference when participants were invited to make decisions. This relationship of pleasure with aggressiveness (Ramírez et al., 2003) has been recently confirmed by other researchers, showing that aggressive behavior (Haller \& Kruk, 2006; Helfritz \& Stanford, 2006; Meier, Robinson, \& Wilkowski, 2006; Peters, Västfjäll, Gärling, \& Slovic, 2006), and even cruelty (Nell, 2006), can be pleasurable. That research offers relevant evidence for the operation of hedonic considerations in decision-making about violence.

It was of interest to compare those results previously obtained in the general population to other ones observed in more specific populations, such as psychiatric patients or prison inmates. For the present study prison inmates were selected because research on this topic is quite sparse. To our knowledge, ours is the first investigation on the relationship between pleasure and aggression performed in a prison (Cabanac, Ramírez, Millana, Toldos-Romero, \& BonniotCabanac, 2007, 2008; Millana, Cabanac, Toldos-Romero, Bonniot-Cabanac, \& Ramírez, 2006).

The following hypotheses were tested:

1) The link between pleasure and the different levels of aggressiveness would have a similar profile in all the populations: the inmates would follow the same tendency previously observed in the general population. This hypothesis is based on our previous analysis on justification of aggression in different cultures suggesting a certain universal moral code, common to all humans (Ramírez, 1991, 1993, 2007b; Ramírez et al., 2001).

2) Inmates would be expected to experience a higher hedonicity level when behaving aggressively, giving their higher impulsivity (Barratt \& Felthous, 2003; Barratt \& Slaughter, 1998) and aggressiveness levels (Ramírez et al., 2005); they believed to be more prone to violence than the general population.

The general implication of the correlation between pleasure and aggressiveness is that individual differences in the strength of hedonic considerations relating to violent responses to conflict have the potential to explain the differences in conducts that are reflected in acquiring a 
criminal record or not. Consequently, this new approach may offer a deeper knowledge of some eventual peculiarities of the criminal population and cast light in the discussions of the programs and policies aimed at preventing future violence, and - just as importantly - the ones that have been shown to fail, or to do more harm than good, in both 'in-patient' settings (i.e., jails and prisons) and 'out-patient' ones (in the community).

\section{METHODS}

\section{Participants}

Two groups of participants served in the study. The first group was recruited from a prison in the suroundings of Madrid: 53 long-term male inmates serving for severe crimes $(37.7 \pm 1.1 \mathrm{yr}$ old). People who were illiterate in Spanish language or possessed psychiatric disturbances were excluded from the study. This group was matched with a non-inmate control group: 75 male university students from two Madrid universities (20.2 $\pm 0.3 \mathrm{yr}$ old). Their participation was voluntary; they received no compensation for it.

\section{Questionnaires}

Participants were invited to answer anonymously three questionnaires that explored the pleasure/displeasure of aggressive behaviors, and their spontaneous level of aggressiveness.

\section{Psychophysics: Questionnaire 1}

Questionnaire 1 (see sample in Appendix 1) explored the hedonistic valence aroused when fifteen minor social conflicts were presented. Participants where placed in different conflict situations, describing an incident that could be seen as insulting, upsetting or offensive to them. Each situation was presented four times, each time ending with a different behavioral response to the social conflict. Thus there were sixty entries in total. The four possible behavioral responses to the unpleasant situations were non-aggressive (passive, i.e. avoidance of confrontation with the perpetrator of the offensive behavior), mildly aggressive (expression of displeasure or disapproval), moderately aggressive (complaint or reprimand), or clearly aggressive. The order of presentation was randomized to remove the possible influence of the rank in presentation of the various items. Half of the participants received Questionnaire 1 with the items in the order of 1 to 60 , and the other half in counterbalanced order, 60 to 1 . To report their experienced hedonicity, participants received a response sheet with 60 parallel lines, as many as items in the Questionnaire; each line was $130 \mathrm{~mm}$ long, with a mark of zero hedonicity located in the middle and pleasure and displeasure on both sides. Participants were instructed to rate the intensity of pleasure or displeasure experienced while reading each item that included a situation, followed by a response. They read the given item, then marked the line at the appropriate analog magnitude of pleasure (right from the middle) or displeasure (left from the middle) they experienced. Thus, what was obtained was an analog estimation of the magnitude of the participant's hedonic (positive or negative) experience when imagining him self in the situation followed by a more or less aggressive behavioral response. The magnitude of aggressiveness was, of course, non-parametric as the four possible responses had been produced using common sense. A similar method has been repeatedly used in previous research (e.g., Cabanac et al., 2002; Ramírez et al., 2005).

\section{Decision: Questionnaire 2}

In order to evaluate the preference for a given aggressive response in these situations, the same fifteen situations described in Questionnaire 1 were presented, each followed by four possible behavioral responses (i.e. 15 entries). In a multiple choice examination type, participants marked which behaviors they would decide to do. The order of aggressiveness magnitude was randomized in each of the 15 situations.

\section{Aggressiveness: Questionnaire 3}

Questionnaire 3, known as the CAMA test, originally constructed by Lagerspetz and Westman (1980), was subsequently revised by Ramirez $(1985,1991,1993)$. The CAMA test estimates the participants' level of spontaneous aggressiveness, measured as the degree of justification of different types of aggressive acts in various situations in which they may be conducted. Because of its relative novelty -even if it has been already used used in many countries: Finland (Lagerspetz \& Westman, 1980; Lagerspetz, Björkqvist, Björkqvist, \& Lundman, 1988), Britain (Benton, Kumari, \& Brain, 1982), Poland (Fraçzek, 1985; Fraçzek, Ramirez, \& Torchalska, 1985), Spain (Ramírez, 1985, 1991, 1993), Japan and the U.S.A. (Fujihara, Kohyama, Andreu, \& Ramírez, 1999; Ramírez \& Fujihara, 1997), Iran (Musazadeh, 1999), India (Ramírez \& Andreu, 2006), and South Africa-, we include it (see Appendix 2) and describe some of its psychometric properties and validated features (Fraçzek, 1985; Lagerspetz \& Björkqvist, 1985; Lagerspetz \& Westman, 1980; Ramírez, 1985, 1991).

\section{RESULTS}

\section{Questionnaire 1 (Hedonicity)}

Both passive and most aggressive responses to the conflict situations were felt unpleasant in both groups, even the degree of declared unpleasantness was lower among the inmates (Student's t: $\mathrm{p}<0.0001$ ). Each population however responded differently to the mildly and moderate aggressive behaviors: inmates described both as pleasant, whereas the control group described them just as slightly unpleasant (Fig. 1).

\section{Questionnaire 2 (Decision Making)}

Table 1 present the mean results from Questionnaire 2, superimposed on the results collected from Questionnaire 1. Both groups selected behaviors with aggressiveness magnitude of approximately 2 , based on a scale of 1 to 4 , and the decisions coincided with the highest pleasure. The results to Questionnaire 2 demonstrate that although inmates rated as less unpleasant than 1 and 4 the behaviors with aggressiveness intensity 3, they did not select them in Questionnaire 2. Both inmates and control participants selected the mild aggressive ones, shunning the least and the most aggressive behaviors. That choice coincided with the results they selected in Questionnaire 1 as maximal pleasure. 

Effect: Controls vs Inmates

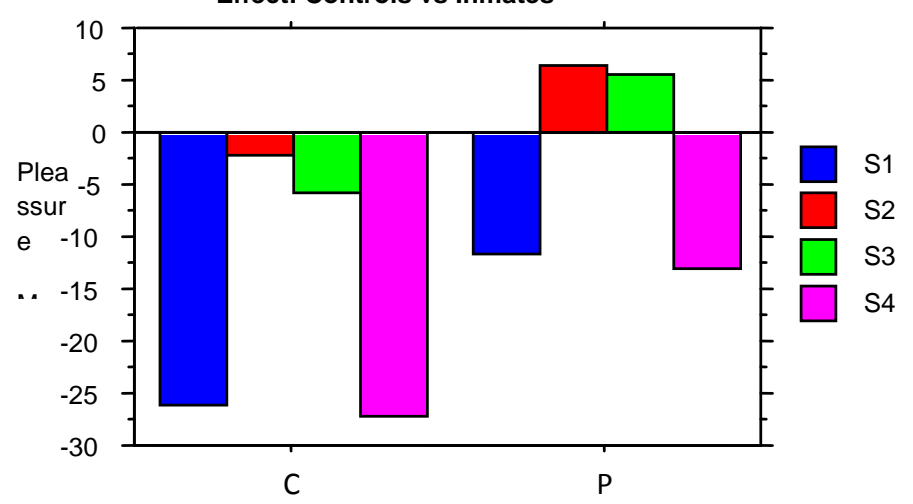

Fig. (1). Questionnaire 1: Ordinates indicate the mean magnitude estimations of hedonicity given by participants, in milimeters (controls, left: inmates, right) to the various items presented. In abscissae, columns 1, 2, 3, and 4 represent increasingly aggression, ranging from no (blue) to slight (red), moderate (green) and highly aggressive response (pink).

Correlations between individual indicators of hedonic ratings and behavior choice were measured to test the hypothesis of covariation of individual hedonistic valence and individual behavior preference: they were significant in both groups.

Table I.

\begin{tabular}{|c|c|c|}
\hline & $\begin{array}{c}\text { Aggressiveness } \\
\text { Cama Test (Median) }\end{array}$ & $\begin{array}{c}\text { Hedonic Rating } \\
\text { (Mean } \pm \text { se) }\end{array}$ \\
\hline \hline $\begin{array}{c}\text { INMATES } \\
\mathrm{N}=53\end{array}$ & 28 & $-32 \pm 22 \mathrm{~mm}$ \\
\hline $\begin{array}{c}\text { CONTROLS } \\
\mathrm{N}=75\end{array}$ & 32 & $-154 \pm 17 \mathrm{~mm}$ \\
$\mathrm{p}$ & $\begin{array}{c}\text { Komogorov-Smirnov } \\
<0.0006\end{array}$ & $\begin{array}{c}\text { Student's } t \\
<0.0001\end{array}$ \\
\hline
\end{tabular}

\section{Questionnaire 3 (Justification of Aggression)}

Justification of aggression, as measured by the CAMA test, correlated positively with the mean magnitude of hedonicity of the behavioral responses selected from Questionnaire 2 in controls both inmates $\left(\mathrm{p}=0.0089^{\circ}\right)$ and control participants $(\mathrm{p}=0.0012)$. The more aggressive participants tended to select more aggressive behaviors on Questionnaire 2 (Fig. 2). The CAMA test results also significantly correlated with the hedonicity of the decisions made.

It is also interesting to mention that, using the Komogorov-Smirnov test, the level of justification of aggression shown by the inmates was significantly lower than the one by the controls $(\mathrm{p}<0.0006)$.

\section{DISCUSSION}

The major point made is that slight and moderate aggressive responses were related to pleasure, or at least to
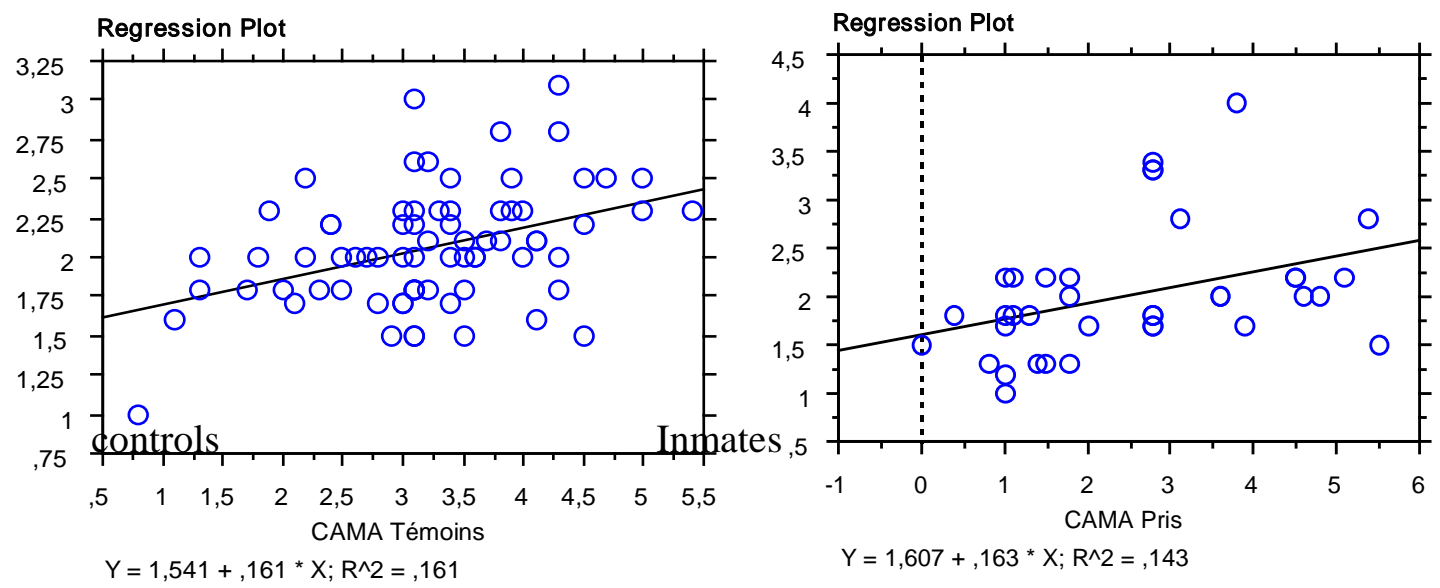

Fig. (2). Correlation between the results from Questionnaire 3 (CAMA test on aggressiveness) and the mean hedonicity evoked by the more or less aggressive behaviors selected by participants from Questionnaire 2 (controls, left: inmates, right). The results of both groups are similar, with no significant differences.

\footnotetext{
${ }^{\circ}$ N.B. Only 37 inmates accepted to answer that CAMA test
} 
removal of displeasure as opposed to creating pleasure, which in the practice means the same, while no aggression or strong aggression were clearly rated as unpleasurable, and that there was an enhancement of the pleasure of aggressiveness in the environment of prisons. Some generally weak to moderate correlation with aggressive behavioural choices was also found.

Hypothesis 1 (the inmate populations would follow the same tendency observed in 'normal' populations) was confirmed. As expected, criminal population showed a bellshaped pattern of hedonicity when possible behavioral responses are ranked according to rising aggressiveness, until a certain level. This pattern is similar to the one obtained by the university population, previously in Quebec (Ramírez, 2003; Ramírez et al., 2005), and now also in Madrid. Inmates rated as pleasant behaviors with aggressiveness intensity 3 in Questionnaire 1, even when they did not select them in Questionnaire 2. This suggests that their eventual decisions might be influenced by different factors, such as a participant's own agreeableness (Meier $e t$ al., 2006), heredity (Marler, Trainor, \& Davis, 2005), previous learning of the consequences of aggression (Carnagey \& Anderson, 2006), or impulsiveness (Ramírez et al., 2005).

Hypothesis 2 (inmates would be expected to experience a higher hedonicity level when behaving aggressively) was also confirmed. Inmates reported more pleasure for higher aggressive responses than control participants did. Of course, a likely explanation is that those admitted to prison are there precisely because they are more aggressive and, consequently, a sample of criminals would be expected to contain more aggressive persons than would be predicted by the base rate for aggression in the general population (Barratt \& Slaughter, 1998). But this acceptance of the obvious existence of different personality traits, embedded in biology, does not preclude other complementary explanations. Violence is a multi-faceted phenomenon resulting from complex interactions among a variety of biological, psychological, and social variables (Ramírez, 2003; Ramírez \& Andreu, 2003). If aggressiveness seems to depend largely on the social environment experienced before adulthood, as has been shown by many researchers (Boivin \& Vitaro, 1995; Kerr, 1994; Lansford et al., 2002; Poulin \& Boivin, 2000), then one could also accept that an enhancement of the pleasure of aggressiveness in the environment of prisons, as the present study shows, should have been expected because, as a person's violence increases, net immediate reinforcement also increases. Among the benefits from violent behavior there are some immediate ones, such as the intrinsic satisfaction of the violent act itself, and other long-term ones, such as a possibly exciting lifestyle (O'Donoghue \& Rabin, 2000; Rachlin, Logue, Gibbon, \& Frankel, 1986). This may also be related to a more aggressive disposition that produced unlawful behaviors.

Another hypothesis, which was given for granted (prison inmates are believed to be more prone to violence than the general population), apparently was rejected by the present results: the Komogorov-Smirnov test showed a significantly lower level of justification of aggression by the inmates than by the controls. These rather intriguing results may be explained by social desirability or self-presentational biases. Inmates would most likely answer in a socially desirable fashion, as part of a strategy to getting an earlier release. Although assured of anonymity, the participants may still have been reluctant to disclose feelings about justification of aggression for fear of reprisals from prison authorities. This reluctance could have biased their decisions and ratings, making them less approving of aggression in comparison to a 'normal' population. The social desirability hypothesis is supported by the non-significant correlations between the responses and the ratings of responses among inmates: their selected responses probably were inconsistent with what they really felt, reflecting instead a desire to please the researchers.

This limitation suggests the convenience of treating more cautiously this kind of studies to ensure accuracy, avoiding an unwanted influence of social desirability and selfpresentational biases on the self-report responses. Its importance however seems minimal in studies, like the present one, where the self-reports about justification of aggression and its degree of pleasureness are compared mainly within the same subjects.

There are some other possible limitations in our design. It may be suspected that vignette methods depend upon sufficient insight into the drivers of one's own reactions to be able to report on or predict them, a dependence that can be unfounded and can lead to misleading conclusions. In other words, we learn what people say what they think they would feel, not what they would feel in reality. Such a possible critique applies to ALL verbal assessment tools: you don't know whether a 'verbal' answer is true, where you would ideally observe real/actual behavior. Still, especially in problematic types of behaviors, vignettes at least have the advantage of offering a 'real life' context. Moreover, vignettes are also used in research with young children. So this method seems to offer sufficient insight. The significant correlation found in the present results between the participants' aggressive decisions and their CAMA tests is a further safeguard against self-report bias, as already argued elsewhere (Ramírez \& Andreu, 2003).

Another possible limitation we acknowledge is that the choice of this specific control group may not have been the most appropriate one for prison inmates. As Raine and Scerbo (1991) suggested, matched non-criminal control groups are necessary to differentiate between crime and violence criterion measures when inmates are subjects. But university students are so different in age, educational level and probably social background that they may not be the most appropriate comparison group. However, the significant correlations found between their profiles and the ones of the inmates proved that its use as a control group did not lead to misleading results.

Now that we have found that aggression can produce pleasure, future research should explore in more detail the hedonic weight distinguishing types of aggressive behavior that an offender may show. Prison-based behavioral characteristics are of considerable value when attempting to create typologies of the different groups (Ireland, 2004). Particularly, following a dichotomic categorization of aggression (Ramírez \& Andreu, 2003), the distinction 
between controlled-instrumental and automatic-impulsive processes should be addressed. For instance, Wann, Carlson, and Schrader (1999) observed a higher willingness to consider instrumental aggressive acts than impulsive aggression. Also, Lowe et al. (2002), investigating the contribution of the instrumental and affective components of attitude, highlighted the affective component as a much more powerful predictor of intention compared to the instrumental component. Since in many cases aggressive behavior is of impulsive nature, the question could be as follows: Does any relationship exist between impulsiveness and the tendency towards maximizing pleasure? Our hypothesis is that, even though reward may be typical of instrumental/proactive aggression, it is not necessarily absent from impulsive aggression, As previous research of our group suggested, people tend to make impulsive decisions as a function of the resulting pleasure they receive (Ramírez et al., 2003). Pleasure would have a fundamental role in aggression decision-making. Therefore, the hedonic experience of a situation would act as a motivation for repeating that behavior. For this purpose, it is quite appropriate to develop instruments that analyze motivations. In that direction, we have recently developed a new version of the CAMA test, devised originally as an instrument for measuring the moral attitudes towards aggression (Ramírez, 1985), distinguishing between hostile-reactive and instrumental-proactive dichotomy of aggression (Andreu, Ramírez, \& Raine, 2006). The significant positive correlation found in the present study between the decisions which are aggressive and the CAMA results provides a new evidence of its validity for estimating the level of aggressiveness in a person.

Another interesting topic to be explored in the future is the analysis of eventual differences related to the justification of different levels of aggression and to their hedonic ratings of them between inmates of different gender. Contrary to the common belief that men are more aggressive and express aggression more frequently or intensely in anger-provoking situations than women (for reviews see: Eagly and Steffen, 1986; White, 1983), women can be aggressive too (Underwood, 2003; Van Goozen, Frijda, \& VanDePoll, 1994). Proneness toward subjective experience of anger and to objective angry expression also seems to be rather universal, even if subject to minor peculiar sexual and cultural differences (Ramírez et al., 2001). Some possible differences between men and women might be due more to the way they expressed their feelings than to how they experienced them (Ramírez, Santisteban, Fujihara, \& Van Goozen, 2002). Furthermore, studying prisoners, Ireland (2000) found slightly higher physical aggression among women than among men, probably attributable to the fact that female prisoners may represent a more extreme part of the population in regard to characteristics such as physical aggression and anger (Suter, Byrne, Byrne, Howells, \& Day, 2002). This might also explain why Cauffman et al. (2005), comparing self-control in juvenile delinquents and normal high-school students of both sexes, found greater differences between female offenders and female students than those between the male offenders and students. We have given elsewhere (Cabanac et al., 2007; Millana et al., 2006) some possible non-mutually exclusive explanations for some small differences on hedonic ratings of aggressive behaviors found between incarcerated criminals of both genders: a) the female participants might have been more honest than men in their responses; b) women might enjoy aggressiveness more than men because they are more inhibited in expressing anger and socially refrained in being aggressive; and/or c) such a mild discrepancy between pleasure and decision might simply reflect a stronger influence of 'political correctness' on the way women express themselves.

In conclusion, in social conflicts, people's behaviors tend to follow the trend to maximize their experienced pleasure; and it seems they may derive pleasure from aggression as long as it is exhibited on a low to moderate level. More precisely, people associate moderate aggression with pleasure -or with removing displeasure: aggressive behaviors of medium intensity were rated as significantly less unpleasant than the most passive and most aggressive behaviors, which were associated with higher displeasure. Similar patterns, previously found in 'normal' populations (Ramírez et al., 2005), are also present in special populations, such as "in-patient" or inmate settings. Such a result is consistent with a fundamental role of hedonicity in decision-making, showing that the trend to maximize pleasure or minimize displeasure when it comes to make an aggressive decision is indeed a deeply rooted mechanism of decision-making that largely transcends cultural biases or pathological borderlines. Thus the pleasure of mild aggressiveness is not characteristic or exclusive of pathologically violent people (Gray, MacCulloch, Smith, Morris, \& Snowden, 2003), but rather a general trait present in everybody (Johnson, Cohen, Smailes, Kasen, \& Brook, 2002; Marler et al., 2005). This trend, though, seems to be stronger in the inmate population, as inmates described higher level of aggression as agreeable. A better understanding of the complex dynamics among pleasure and aggression helps put things in perspective and potentially can reconcile conflicting observations as well as it promises to refine therapy and prevention of violence.

\section{APPENDIX 1: SAMPLES OF QUESTIONNAIRES 1 AND 2}

\section{Questionnaire 1}

The respondents are asked four times to imagine being in each of 15 situations. A specific action tendency that is tailored to the situation under consideration is suggested in response to each question. The respondents have to indicate how intense pleasure or displeasure they would feel when experiencing each specific action.

1- You are in a parking lot waiting for a free space. Just when you find a free place, another driver arrives and takes it in your presence.

a- Look for another space

2- You are in a movie theatre and behind you there are two persons who are talking loudly. They disturb you

a- Move to another seat

3- You are on a train. In your compartment, arrives a mother with a noisy child.

a- Move to another compartment 
4- You are watching television in a dormitory. A group of people enter and, without saying anything, they change the channel.

a- Leave without saying anything.

5- You are waiting for some friends and decide to buy some nice fruits as a dessert. When you arrive home, you realize that half of them are rotten.

a- Forget about the fruits. Offer your guests something different for dessert.

6- You are on a crowded bus. An old, tired lady arrives and asks a young person to give up his seat. The young person refuses.

a- Go to the back of the bus to avoid any conflict.

7- You are in a parking lot waiting for a free space. Just when you find a free place, another driver arrives and takes it in your presence.

b- Honk your horn to show your displeasure.

Etc. (Translated from Spanish).

\section{Questionnaire 2}

The respondents are asked to imagine being in each of 15 situations and to indicate what they would feel inclined to do. Each vignette offers four possible behavioral responses of different intensity levels, that are tailored to the situation under consideration.

1- You are in a parking lot waiting for a free space. Just when you find a free place, another driver arrives and takes it in your presence.

a. Look for another space.

b. Honk your horn to show your displeasure.

c. Get out of your car and argue with the person.

d. Get out or your car and kick the person's car with your foot.

2- You are in a movie theatre and behind you there are two persons who are talking loudly. They disturb you.

a. Move to another seat.

b. Make an exasperating sound, indicating your displeasure.

c. Ask them to stop talking.

d. Find the usher and tell him to stop the people from talking.

3- You are on a train. In your compartment, arrives a mother with a noisy child.

a. Move to another compartment.

b. Ask the child to behave.

c. Tell, with an impatient voice, the motherto control her child.

d. Chastise and slap the child.

4- You are watching television in a dormitory. A group of people enter and, without saying anything, they change the channel.

a. Leave without saying anything.

Etc. (Translated from Spanish)

\section{APPENDIX 2: CAMA TEST (TRANSLATED FROM SPANISH)}

Aggression has proven to be a serious problem in society today. In this research we try to investigate how people relate to different types of aggressive acts. It is only natural that we all get angry in certain situations. Sometimes we would even feel it wrong not to get angry.

Below we present six situations in which some aggressive act might occur. We mention eight possible aggressive acts. We ask you to estimate if in your opinion each act is usually justified or not in each situation.

\section{List of Situations}

1. In self-defense

2. To protect another person

3. When communication breaks down

4. When angry

5. To protect one's property

6. As a punishment

\section{List of Aggressive Acts}

1. To be ironical

2. To threaten

3. To stop somebody from doing something

4. To use torture

5 . To shout angrily

6. To hit another person

7. To get furious

8. To kill another person

\section{REFERENCES}

Ajzen, I. (1991). The theory of planned behavior. Organizational Behavior and Human Decision Processes 50, 179-211.

Andreu, J. M., Ramírez, J. M., \& Raine, A. (2006). Un modelo dicotomico de agresión y su evaluación mediante dos autoinformes: el CAMA y el RPQ. Psicopatologia Clinica, Legaly Forense 5, 25-42.

Balaskó, M., \& Cabanac, M. (1998). Grammatical choice and affective experience in a second-language test. Neuropsychobiology 37, 205210.

Barratt, E. S., \& Felthous, A. R. (2003). Impulsive versus premeditated aggression: implications for men's real decisions. Behavioral Science and the Law 16, 285-302.

Barratt, E. S., \& Slaughter, L. (1998). Defining, measuring, and predicting impulsive aggression: an heuristic model. Behavioral Sciences and the Law 16, 285-302.

Benton, D., Kumari, N., \& Brain, P. F. (1982). Mild hypoglycaemia and questionnaire measures of aggression. Biological Psychology 14, 129-135.

Boivin, M., \& Vitaro, F. (1995). The impact of peer relationship on aggression in childhood: inhibition through coercion or promotion through peer support. In M. J. (Ed.), Coecion and Punishment in Long-Term Perspectives (pp. 183-197). New York: Cambridge University Press.

Bushman, B. J., Baumeister, R. F., \& Phillips, C. M. (2001). Do people aggress to improve their mood? Catharsis beliefs, affect regulation opportunity, and aggressive responding. Journal of Personality and Social Psychology 81, 17-32.

Cabanac, M. (1971). Physiological role of pleasure. Science 173, 1103 1107. 
Cabanac, M. (1979). Sensory pleasure. Quarterly Review of Biology 54, 129.

Cabanac, M. (1986). Money versus pain: experimental study of a conflict in humans. Journal of the Experimental Analysis of Behavior 46, $37-$ 44.

Cabanac, M. (1992). Pleasure: the common currency. Journal of Theoretical Biology 155, 173-200.

Cabanac, M. (1996). Pleasure and joy, and their role in human life. Paper presented at the Indoor Air '96, Nagoya.

Cabanac, M., Duclaux, R., \& Spector, N. H. (1971). Sensory feedbacks in regulation of body weight: is there a ponderostat? Nature 229, 125127.

Cabanac, M., Guillaume, J., Balasko, M., \& Fleury, A. (2002). Pleasure in decision-making situations. BMC Psychiatry 2, 7.

Cabanac, M., Pouliot, C., \& Everett, J. (1997). Pleasure as a sign of efficacy of mental activity. European Psychologist 2, 226-234.

Cabanac M., Ramírez J.M., Millana L., Toldos-Romero, M.P., \& BonniotCabanac M-C. (2007). The pleasure of being aggressive in prison inmates. $19^{\text {th }}$ Association for Psychological Science, Washington DC. May 24-27.

Cabanac, M., Ramírez, J.M., Millana, L., Toldos-Romero, M.P., \& BonniotCabanac, M-C. (2008). The Pleasure of Aggressiveness Among Inmates in Preventive and LongTerm Detention. The Open Criminology Journal 2008, 1 (2), 19-26.

Carnagey, N. L., \& Anderson, C. A. (2006). The effects of reward and punishment in violent video games on aggressive affect, cognition, and behavior. Psychological Science 16, 882-889.

Cauffman, E., Scolle, S. H., \& Mulvey, E. (2005). Predicting first-time involvementin the juvenile justice system among emotionally disturbed youth receiving mental health services. Psychological Services 2, 28-38.

Eagly, A. H., \& Steffen, V. J. (1986). Gender and aggressive behavior: a metanalytic review of the social psychological literature. Psychological Bulletin 100, 309-330.

Fishbein, M., \& Ajzen, I. (1975). Belief, Attitude, Intention, and Behavior: an Introduction to theory and research. Don Mills, Ontario: Addison-Wesley Pub. Co.

Fraçzek, A. (1985). Moral approval of aggressive acts: a Polish-Finish comparative study. Journal of Cross-Cultural Psychology 16, 4154.

Fraçzek, A., Ramirez, J. M., \& Torchalska, B. (1985). Attitudes toward interpersonal aggression. In F. LeMoli (Ed.), Multidisciplinary Approach to Conflict and Appeasement in Animals and Man (pp. 182). Parma: Instituto di Zoologia.

Fujihara, T., Kohyama, T., Andreu, J. M., \& Ramírez, J. M. (1999). Justification of interpersonal aggression in Japanese, American, and Spanish students. Aggressive Behavior 25, 185-195.

Geen, R., \& Quanty, M. (1977). The catharsis of aggression: an evaluation of a hypothesis. In L. Berkovitz (Ed.), Advances in Experimental Social Psychology (Vol. 10, pp. 1-37). New York: Academic Press.

Gray, N. S., MacCulloch, M. J., Smith, J., Morris, M., \& Snowden, R. J. (2003). Forensic psychology: violence viewed by psychopathic murderers. Nature 423, 497-498.

Haller, J., \& Kruk, M. R. (2006). Normal and abnormal aggression: human disorders and novel laboratory models. Neuroscience \& Biobehavioral Reviews 30, 292-303.

Helfritz, L. E., \& Stanford, M. S. (2006). Personality and psychopathology in an impulsive aggressive college sample. Aggressive Behavior 32, 28-37.

Hrubes, D., Ajzen, I., \& Daigle, J. (2001). Predicting hunting intentions and behavior. An application of the theory of planned behavior. Leisure Sciences 23, 165-178.

Ireland, J. L. (2000). Bullying amongst prisoners. University of Central Lancashire: Preston.

Ireland, J. L. (2004). Anger management therapy with young male offenders: an evaluation of treatment outcome. Aggressive Behavior 30, 174-185.

Johnson, J. G., Cohen, P., Smailes, E. M., Kasen, S., \& Brook, J. S. (2002). Television viewing ans aggressive behavior during adolescence and adulthood. Science 295, 2468-2471.

Johnson, K. G., \& Cabanac, M. (1983). Human thermoregulatory behavior during a conflict between cold discomfort and money. Physiology \& Behavior 30, 145-150.

Kerr, J. H. (1994). Understanding soccer hooliganism. Philadelphia: Open University Press.
Lagerspetz, K., \& Björkqvist, K. (1985). The moral approval of aggression inventory - revised version. In M. Ramirez (Ed.) (Unpublished).

Lagerspetz, K., \& Westman, M. (1980). Moral approval of aggressive acts. A preliminary investigation. Aggressive Behavior 6, 119-130.

Lagerspetz, K. M. J., Björkqvist, K., Björkqvist, H., \& Lundman, H. (1988). Moral approval of aggression and sex role identity in officer trainees, conscientious objectors to military service, and in a female reference group. Aggressive Behavior 14, 303-313.

Lansford, J. E., Dodge, K. A., Pettit, G. S., Bates, J. E., Crozier, J., \& Kaplow, J. (2002). A 12-year prospective study of the long-term effects of early child physical maltreatment on psychological, behavioral, and academic problems in adolescence. Archives of Pediatrics \& Adolescent Medicine 156, 824-830.

LeBoeuf, R. A., \& Shafir, E. B. (2005). Decision making. In K. J. Holyoak \& R. G. Morrisson (Eds.), The Cambridge Handbookof Thinking and Reasoning (pp. 243-265). New York: Cambridge University Press.

Lowe, R., Eves, F., \& Carroll, D. (2002). The influence of affective and instrumental beliefs on exercise intentions and behavior: a longitudinal analysis. Journal of Applied Social Psychology 32, 1241-1252.

Marler, C., Trainor, B. C., \& Davis, E. (2005). Paternal behavior and offspring aggression. Current Directions in Psychological Science $14,163-166$.

McFarland, D. J., \& Sibly, R. M. (1975). The behavioural final common path. Philosophical Transactions of the Royal Society 270, 265293.

McNamara, J. M., \& Houston, A. I. (1986). The common currency for behavioural decisions. American Naturalist 127, 358-378.

Meier, B. P., Robinson, M. D., \& Wilkowski, B. M. (2006). Turning the other cheek. Agreeableness and the regulation of aggression-related primes. Psychological Science 17, 136-142.

Millana, L., Cabanac, M., Toldos-Romero, M.P., Bonniot-Cabanac, M.C. \& Ramírez, J.M. (2006). Placer asociado con la conducta agresiva en una muestra de reclusos españoles en prisión preventiva. Psicopatología Clínica, Legaly Forense 5, 119-132.

Musazadeh, Z. (1999). Agresión y su justificación: un estudio comparado de studiantes iraníes y españoles. Universidad Complutense, Madrid.

Nell, V. (2006). Cruelty's rewards: the gratifications of perpetrators and spectators. Behavioral and Brain Sciences 29, 211-224.

O'Donoghue, T., \& Rabin, M. (2000). The economics of immediate gratification. Journal of Behavioral Decision Making 13, 233-250.

Peters, E., Västfjäll, D., Gärling, T., \& Slovic, P. (2006). Affect and decision topic: a "hot" topic. Journal of Behavioral Decision Making 19, 79-85.

Poulin, F., \& Boivin, M. (2000). The role of proactive and reactive aggression in the formation and development of boys' friendships. Developmental Psychology 36, 233-240.

Rachlin, H., Logue, A. W., Gibbon, J., \& Frankel, M. (1986). Cognition and behavior in studies of choice. Psychological Review 93, 33-45.

Raine, A., \& Scerbo, A. (1991). Theories of violence. In J. S. Milner (Ed.), Neuropsychology of Aggression (pp. 1-25). Borton: Kluwer Academic Publishers.

Ramírez, J. M. (1985). Attitudes toward aggression in four Spanish regions. In F. L. Moli (Ed.), Multidisciplinary approaches to conflict and appeassement in animals and man (pp. 63). Parma: INstituto di Zoologia.

Ramírez, J. M. (1991). Similarities in attitudes toward interpersonal aggression in Finland, Poland, and Spain. Journal of Social Psychology 131, 737-739.

Ramírez, J. M. (1993). Acceptability of aggression in four Spanish regions and a comparison with other European countries. Aggressive Behavior 19, 185-197.

Ramírez, J. M. (2003). Human aggression: a Multifaceted Phenomenon. Madrid: Centreur.

Ramírez, J. M. (2007a). Justification of aggression in several Asian and European countries with different religious and cultural backgrounds. International Journal of Behavioral Development 31, 9-15.

Ramírez, J. M. (2007b). Televisión y violencia. Revista Latinoamericana de Psicologia 39, 327-349.

Ramírez, J. M., \& Andreu, J. M. (2003). Types of aggression. International Review of Social Psychology 16, 125-141.

Ramírez, J. M., \& Andreu, J. M. (2006). Aggression, and some related psychological constructs (anger, hostility, and impulsivity); some 
comments from a research project. Neuroscience and Biobehavioral Reviews 30, 276-291.

Ramírez, J. M., Bonniot-Cabanac, M. -C., \& Cabanac, M. (2003). Impulsive aggression and pleasure. In J. M. Ramírez (Ed.), Human Aggression (pp. 449-472). Madrid: Centreur.

Ramírez, J. M., Bonniot-Cabanac, M.-C., \& Cabanac, M. (2005). Can aggression provide pleasure? European Psychologist 10, 136-145.

Ramírez, J. M., \& Cabanac, M. (2003). Pleasure, the common currency of emotions. In P. Ekman, J. J. Campos, R. J. Davidson \& F. B. M. de Waal (Eds.), Emotions Inside Out: 130 Years after Darwin's The expression of the Emotions in Man and Animals (Vol. 1000). New York: New York Academy of Sciences.

Ramírez, J. M., \& Fujihara, T. (1997). Cross-cultural study of attitudes toward interpersonal aggression (in Japanese, with a summary in English). Kwansei Gakuin Sociology Studies 78, 97-103.

Ramírez, J. M., Lagerspetz, K. M., Fraczek, A., Fujihara, T., Theron, W. H., Musazadeh, Z., Andreu, J.M. (2001). Moral approval of aggressive acts by urban students: a cross-national study on four continents. In: J. M. Ramírez \& D. S. Richarson (Eds.), Cross-Cultural Approaches to Aggression and Reconciliation (pp. 61-67). Huntington, N.Y.: Nova Science Publishers, Inc.

Ramírez, J. M., Santisteban, C., Fujihara, T., \& Van Goozen, S.H.M (2002). Differences between experiences of anger and readiness to angry action: a study of Japanese and Spanish students. Aggressive Behavior 23(6): 429-438.
Russell, G. (2004). Sport riots: a social-psychological review. Aggression and Violent Behavior 9, 353-378.

Schreurs, B., Derous, E., DeWitte, K., Proost, K., Andriessen, M., \& Glabeke, K. (2005). Attracting potential applicants to the military: the effects of initial face-to-face contacts. Human Performance 18, 105-122.

Suter, J. M., Byrne, M. K., Byrne, S., Howells, K., \& Day, A. (2002). Anger in prisoners: women are different from men. Personality snd Individual Differences 32, 1087-1100.

Underwood, M. K. (2003). Social Aggression Among Girls. New York: The Guilford Press.

Van Goozen, S.H.M., Frijda, N. H., \& Van De Poll, N. E. (1994). Anger and aggression in women: influence of sport choice and testosterone administration. Aggressive Behavior 20, 213-222.

Wann, D. J., Carlson, J. D., \& Schrader, M. P. (1999). The impact of team identification on the hostile and instrumental verbal aggression of sport spectators. Journal of Social Behavior and Personality 14, 279-286.

White, J. (1983). Sex and gender issues in aggression research. In: R. G. Geen \& E. I. Donnerstein (Eds.), Aggression: Theoretical and Empirical Reviews (Vol. 2 Issues in Research, pp. 1-26). New York: Academic Press.

Zubieta, J. K., Yau, W. Y., \& Scott, D. J. (2006). Belief or need? Accounting for individual variations in the neurochemistry of the placebo effect. Brain Behavior and Immunity 20, 15-26.

Received: October 10, 2008

Revised: March 17, 2009

Accepted: March 17, 2009

(C) Ramírez et al.; Licensee Bentham Open.

This is an open access article licensed under the terms of the Creative Commons Attribution Non-Commercial License (http: //creativecommons.org/licenses/by$\mathrm{nc} / 3.0 /$ ), which permits unrestricted, non-commercial use, distribution and reproduction in any medium, provided the work is properly cited 